\title{
Efeitos da irrigação localizada na granulometria e em atributos químicos de um Neossolo Quartzarênico cultivado com coqueiro anão ${ }^{1}$
}

\author{
Effect of localized irrigation on granulometry and chemical attributes of a \\ Quartzipsamment soil cultivated with dwarf coconut
}

\author{
Francisco Alisson da Silva Xavier ${ }^{2 *}$, Rodrigo de Castro Tavares ${ }^{3}$, Gleidson Vieira Marques ${ }^{4}$, Fábio Miranda \\ Rodrigues $^{5}$ e Teógenes Senna de Oliveira ${ }^{6}$
}

\begin{abstract}
Resumo - Objetivou-se avaliar o efeito da irrigação localizada sobre a granulometria, pH e teores de nutrientes de um Neossolo Quartzarênico cultivado com coqueiro anão em área de perímetro irrigado no estado do Ceará. O estudo foi conduzido no campo experimental da Embrapa Agroindústria Tropical/CNPAT, situado no município de Paraipaba, CE. Foram selecionadas e amostradas duas áreas sob fertirrigação utilizando microaspersores do tipo difusor e rotativo. Comparações foram feitas entre pontos definidos na área sob influência da irrigação e pontos fora da área de alcance do microaspersor. Amostras de solo foram coletadas nas distâncias horizontais de 0,$30 ; 0,60 ; 0,90 ; 1,20 ; 1,50 ; 1,80 ; 2,10 ; 2,40$ e 2,70 m a partir da planta, nas profundidades de $0-10 ; 10-20 ; 20-30 ; 30-40$ e $40-50 \mathrm{~cm}$. Foram quantificados os teores de areia, silte e argila; os teores de $\mathrm{Ca}^{2+}$, $\mathrm{Mg}^{2+}$ e K $\mathrm{K}^{+}$trocáveis, $\mathrm{P}$ disponível, $\mathrm{pH}$ e a condutividade elétrica do extrato de saturação. $\mathrm{Na}$ área do emissor tipo difusor ocorreu aumento significativo de $1 \%$ nos teores de argila em subsuperfície, o que pode estar associado ao processo de dispersão das argilas pela presença de $\mathrm{Na}^{+}$trocável na água de irrigação. A irrigação favoreceu acúmulo de $\mathrm{Ca}^{2+}, \mathrm{Mg}^{2+}$ e $\mathrm{P}$ disponíveis nas proximidades dos microaspessores em superfície, e de $\mathrm{Na}^{+}$em profundidade. $\mathrm{O}$ acréscimo de $\mathrm{Na}^{+}$em profundidade implica em um potencial risco de salinização, sugerindo que o manejo da irrigação deve considerar não somente o tipo de microaspersor, mas especialmente a qualidade da água de irrigação e as características físicas e químicas do solo.
\end{abstract}

Palavras-chave - Cocos nucifera. Fertirrigação. Perímetro irrigado. Salinização. Solo arenoso.

\begin{abstract}
The objective of this study was to evaluate the effect of located irrigation on the soil granulometry, $\mathrm{pH}$ and nutrient contents of a Quartzipsamments soil cultivated with dwarf coconut. The study was conducted at the experimental station of Embrapa Agroindústria Tropical/CNPAT, located at Paraibapa County, state of Ceará, Brazil. Two areas under fertirrigation using two models of microsprinklers (diffuser and rotative) were selected. Comparisons were made between irrigated area and non-irrigated area. Soil samples were taken from horizontal distances of $0.30 ; 0.60 ; 0.90 ; 1.20 ; 1.50 ; 1.80 ; 2.10 ; 2.40 \mathrm{e}$ $2.70 \mathrm{~m}$ from each plant in the $0-10 ; 10-20 ; 20-30 ; 30-40$ e $40-50 \mathrm{~cm}$ layers. The measured soil variables were sand, silt and clay contents; available $\mathrm{Ca}^{2+}, \mathrm{Mg}^{2+}, \mathrm{K}^{+}$and $\mathrm{P} ; \mathrm{pH}$ and soil electrical conductivity. In the area adopting diffuser microsprinkler occurred an increase of $1 \%$ in the clay content at the soil subsurface, which may be attributed to clay dispersion process due to the presence of available $\mathrm{Na}+$ ions in the irrigation water. The fertirrigation favored accumulation of $\mathrm{Ca}^{2+}, \mathrm{Mg}^{2+}$ e $\mathrm{P}$ at the neighborhood of the microsprinklers in the soil surface, and increase of available $\mathrm{Na}^{+}$in the deeper soil layers. The increase of $\mathrm{Na}^{+}$in the soil profile suggests the increase of potential hazard of soil salinization, thus the management of irrigation must consider not only the type of microsprinkler but also the quality of water used in the irrigation associated to the soil physical and chemical properties.
\end{abstract}

Key words - Cocos nucifera. Fertirrigation. Irrigated lands. Salinization. Sandy soils.

\footnotetext{
* Autor para correspondência

'Recebido para publicação em 09/09/2010; aprovado em 09/08/2011

Projeto de pesquisa financiado pelo CNPq

${ }^{2}$ Embrapa Mandioca e Fruticultura, Cruz das Almas-BA, Brasil, alisson@enpmf.embrapa.br

${ }^{3}$ Programa de Pós-Graduação em Solos e Nutrição de Plantas, Universidade Federal de Viçosa/UFV, Viçosa-MG, Brasil, rocatavares@yahoo.com.br ${ }^{4}$ Universidade Federal Rural do Semi-Árido/UFERSA, Mossoró-RN, Brasil, alixavi@gmail.com

${ }^{5}$ Centro Nacional de Pesquisa da Agroindústria Tropical, CNPAT-EMBRAPA, Fortaleza-CE, Brasil, alixavi@gmail.com

${ }^{6}$ Departamento de Ciências do Solo, CCA/UFC, 60455-760, Fortaleza-CE, Brasil, teo@ufc.br
} 


\section{Introdução}

Nos sistemas agrícolas modernos tornou-se frequente o uso da fertirrigação como uma das alternativas para a obtenção de incrementos na produtividade das culturas, principalmente de fruteiras no Nordeste do Brasil. Essa região apresenta condições climáticas favoráveis ao cultivo irrigado, o que permite produção durante o período de entressafra de outras regiões, promovendo maior rentabilidade na atividade. A prática da irrigação tem sido considerada uma alternativa viável para a inclusão de áreas agrícolas em regiões áridas e semiáridas (LOPES et al., 2008). Realizada de forma adequada e eficiente, a irrigação torna-se uma ferramenta fundamental no manejo dos sistemas agrícolas, suprindo e/ ou complementando o conteúdo de água no solo às culturas em períodos de déficit hídricos (MEDEIROS et al., 2005).

A despeito dos benefícios da irrigação, é comum a intensificação dos cultivos com o uso ineficiente desta prática, o que na maioria das vezes resulta na perda da qualidade do solo e abandono das áreas agrícolas. Nesse cenário, atenção especial deve estar voltada para o manejo do solo, das culturas e da água de irrigação, especialmente em áreas agrícolas inseridas em perímetros irrigados, visando evitar a degradação do solo e, por consequência, a diminuição da produtividade das culturas (CARLESSO et al., 2007; LYRA et al.,1995). O manejo inadequado da fertirrigação pode causar também a poluição e eutrofização de mananciais, aumentando os custos com adubação e favorecendo a degradação dos agroecossistemas (HERNANI et al., 1999). Portanto, o uso eficiente do solo e da água em perímetros irrigados configura-se como único meio capaz de manter a sustentabilidade dessas áreas (SANTOS; RIBEIRO, 2000).

O uso da irrigação afeta diretamente os atributos químicos do solo (CORRÊA et al., 2009), principalmente em solos com baixo teor de argila e matéria orgânica. Por exemplo, Sobral e Nogueira (2008) verificaram que a aplicação da uréia via água de irrigação causou decréscimo

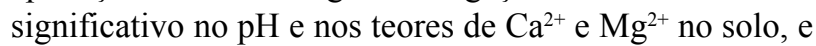
ao longo do tempo, a aplicação de $2.565 \mathrm{~g}$ de $\mathrm{N}$ na forma de uréia acentuou a acidificação do solo. Em adição, Nunes et al. (2008) avaliando características químicas de solos irrigados com água de poços tubulares da região de Janaúba (MG) encontraram que a irrigação, e as práticas culturais associadas, provocam alterações nos solos equivalentes a uma calagem em doses elevadas, causando forte elevação dos valores médios de $\mathrm{pH}$, bem como dos teores de $\mathrm{Ca}^{2+}$ e $\mathrm{Na}^{+}$dos solos. Os autores reportaram ainda que a concentração de sais solúveis na solução do solo ocorreu em camadas intermediárias do perfil, devido à lixiviação. Desta forma, avaliar a influência da irrigação sobre os atributos físicos e químicos do solo é de fundamental importância para o plano de manejo e uso sustentável de sistemas agrícolas irrigados.

Sob a hipótese de que o sistema de irrigação localizada afeta o comportamento de atributos físicos e químicos do solo, condicionando o desenvolvimento das plantas, o presente estudo objetivou avaliar o efeito da irrigação localizada utilizando dois tipos de microaspersores sobre a granulometria, $\mathrm{pH}$ e teores de nutrientes de um Neossolo Quartzarênico cultivado com coqueiro anão em área de perímetro irrigado no estado do Ceará.

\section{Material e métodos}

O estudo foi conduzido no Campo Experimental do Curu (3.200 ha), pertencente à Embrapa Agroindústria Tropical, localizado no município de Paraipaba ( $3^{\circ} 17^{\prime} \mathrm{S}, 39^{\circ} 15^{\prime} \mathrm{W}$ e altitude de $20 \mathrm{~m}$ ) Estado do Ceará. $\mathrm{Na}$ área ocorre o predomínio de cultivos de culturas perenes e o uso de irrigação por aspersão convencional e localizada por microaspersão. O clima é tropical chuvoso Aw' de acordo com a classificação de Köppen, apresentando médias anuais de temperatura e precipitação de $27{ }^{\circ} \mathrm{C}$ e $1.238 \mathrm{~mm}$, respectivamente (IPECE, 2005). A vegetação característica é complexo vegetacional da zona litorânea (IPECE, 2005), sendo observada a presença de caatinga hiperxerófila e transição de floresta-caatinga (BRASIL, 1973).

A área selecionada para o experimento estava sendo cultivada com coqueiro anão (Cocos nucifera L.) por um período de 30 meses na época da coleta do solo. As amostras foram coletadas de um Neossolo Quartzarênico cuja caracterização físico-química encontra-se na Tabela 1.

Foram amostradas duas parcelas fertirrigadas, uma que utilizava microaspesores do tipo difusor (modelo DANJET) e outra que adotou microaspersores do tipo rotativo (modelo DAN 2001). A água utilizada na irrigação foi proveniente do Rio Curu, cuja caracterização verifica-se na Tabela 2. Ambos emissores, difusor e rotativo, eram do tipo autocompensantes apresentando vazões de 57 e $55 \mathrm{~L} \mathrm{~h}^{-1}$ em pressão de serviço entre 1 a 1,5 bar e raios de alcance máximo de 1,80 e 2,40 m, respectivamente. Para efeito comparativo foi conveniente avaliar o comportamento das variáveis analisadas de acordo com o raio de atuação de cada microaspersor nas duas áreas de estudo. Desta forma, o raio de alcance da área com o emissor do tipo difusor (AED) caracterizou uma condição irrigada (CI), enquanto que os demais pontos uma condição não irrigada (CNI). O mesmo procedimento foi adotado para a área do emissor do tipo rotativo (AER), onde apenas um ponto, após $2,40 \mathrm{~m}$, caracterizou a CNI. 
Tabela 1 - Caracterização física e química do solo

\begin{tabular}{lrrrrr}
\hline \multirow{2}{*}{ Atributos } & \multicolumn{5}{c}{ Profundidade $(\mathrm{cm})$} \\
\cline { 2 - 5 } & $0-10$ & $10-20$ & $20-30$ & $30-40$ & $40-50$ \\
\hline Areia $\left(\mathrm{g} \mathrm{kg}^{-1}\right)$ & & & & & \\
$2-1 \mathrm{~mm}$ & 41,6 & 46,5 & 42,0 & 43,7 & 44,9 \\
$1-0,5 \mathrm{~mm}$ & 147,3 & 159,9 & 157,7 & 169,5 & 158,3 \\
$0,5-0,25 \mathrm{~mm}$ & 332,2 & 355,7 & 347,6 & 336,2 & 318,4 \\
$0,25-0,105 \mathrm{~mm}$ & 296,6 & 302,7 & 313,2 & 302,6 & 310,2 \\
$0,105-0,053 \mathrm{~mm}$ & 46,9 & 44,1 & 41,1 & 40,8 & 50,2 \\
Silte $\left(\mathrm{g} \mathrm{kg}^{-1}\right)$ & 79,3 & 37,8 & 47,2 & 51,7 & 57,7 \\
Argila $\left(\mathrm{g} \mathrm{kg}^{-1}\right)$ & 56,0 & 53,2 & 50,8 & 55,5 & 60,2 \\
$\mathrm{pH}\left(\mathrm{KCl}^{-1}\right.$ & 6,1 & 5,8 & 5,9 & 5,9 & 5,9 \\
$\mathrm{P} \mathrm{disponível}\left(\mathrm{mg} \mathrm{kg}^{-1}\right)$ & 1,3 & 1,5 & 0,6 & 0,4 & 0,3 \\
$\mathrm{Na}^{+}\left(\mathrm{cmol}_{\mathrm{c}} \mathrm{dm}^{-3}\right)$ & 0,05 & 0,02 & 0,01 & 0,00 & 0,05 \\
$\mathrm{~K}^{+}\left(\mathrm{cmol}_{\mathrm{c}} \mathrm{dm}^{-3}\right)$ & 0,7 & 0,5 & 0,4 & 0,3 & 0,3 \\
$\mathrm{Ca}^{2+}\left(\mathrm{cmolc} \mathrm{dm}^{-3}\right)$ & 3,2 & 2,5 & 2,3 & 2,3 & 2,5 \\
$\mathrm{Mg}^{2+}\left(\mathrm{cmol}_{\mathrm{c}} \mathrm{dm}^{-3}\right)$ & 0,7 & 0,5 & 0,7 & 0,7 & 0,6 \\
$\mathrm{CEes}^{-3}\left(\mathrm{dS} \mathrm{m}^{-1}\right)$ & 0,1 & 0,1 & 0,1 & 0,1 & 0,1 \\
\hline
\end{tabular}

${ }^{\text {a }}$ CEes: condutividade elétrica do extrato de saturação

Tabela 2 - Características químicas da água de irrigação do Rio Curu situado no município de Paraipaba, CE

\begin{tabular}{|c|c|c|c|c|c|c|c|}
\hline $\mathrm{Ca}^{2+}$ & $\mathrm{Mg}^{2+}$ & $\mathrm{K}^{+}$ & $\mathrm{Na}^{+}$ & $\mathrm{CEa} / \mathrm{a}$ & $\mathrm{RAS}^{/ \mathrm{b}}$ & $\mathrm{pH}(\mathrm{KCl})$ & Classificação \\
\hline - & ----- 1 & $\cdots$ & -1---- & $\mathrm{dS} \mathrm{m}^{-1}$ & $\%$ & & \\
\hline 1,02 & 1,43 & 0,19 & 4,15 & 0,6 & 3,75 & 7,4 & $\mathrm{C} 2 \mathrm{~S} 1 / \mathrm{c}$ \\
\hline
\end{tabular}

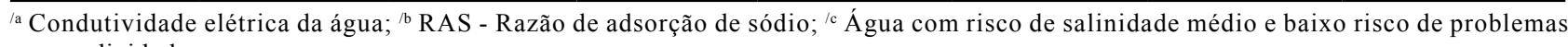
com sodicidade

A adubação da área experimental foi realizada de acordo com os requerimentos nutricionais para a cultura do coqueiro (SOBRAL, 1997). A adubação fosfatada e orgânica foi incorporada ao solo no plantio e parceladas a cada seis meses, em sulcos de $10 \mathrm{~cm}$ de profundidade e distanciados de 60; 90 e $120 \mathrm{~cm}$ ao redor das plantas nos primeiros $12 ; 24$ e 30 meses, respectivamente. A adubação orgânica foi realizada por meio da aplicação de 7; 10 e 10 litros de esterco bovino por planta nas etapas de plantio, 12 e 24 meses após o plantio, respectivamente. Para as mesmas épocas aplicou-se $800 ; 400$ e $1.400 \mathrm{~g}$ de superfosfato simples por planta, respectivamente. A uréia e o cloreto de potássio foram aplicados a cada 15 dias via fertirrigação.

O espaçamento do coqueiro foi de 7,5 x 7,5 m em triângulo (FIG. 1). Um microaspersor foi instalado à $0,50 \mathrm{~m}$ de distância de cada planta, totalizando três microaspersores por área amostrada. Amostras de solo foram coletadas nas profundidades de 0 a 10; 10 a 20; 20 a 30; 30 a 40 e 40 a $50 \mathrm{~cm}$, em pontos dispostos linearmente a partir de $0,30 \mathrm{~m}$ de cada planta, distanciados um do outro em $30 \mathrm{~cm}$. Portanto, as distâncias amostradas a partir de cada planta foram: 0,$30 ; 0,60 ; 0,90 ; 1,20 ; 1,50 ; 1,80 ; 2,10$; 2,40 e 2,70 m, totalizando 54 pontos por cada camada. Posteriormente, foi realizada a redução do número de amostras por meio da união das 54 amostras simples, obtendo-se 27 amostras compostas de acordo com o esquema apresentado na Figura 1.

O procedimento adotado para a obtenção das amostras compostas partiu da premissa de que os nove primeiros pontos amostrados em relação à planta (até 2,70 m de distância) entre um dos lados do triângulo e o seu lado adjacente configuraram amostras dispostas simetricamente, portanto, para as condições do presente 


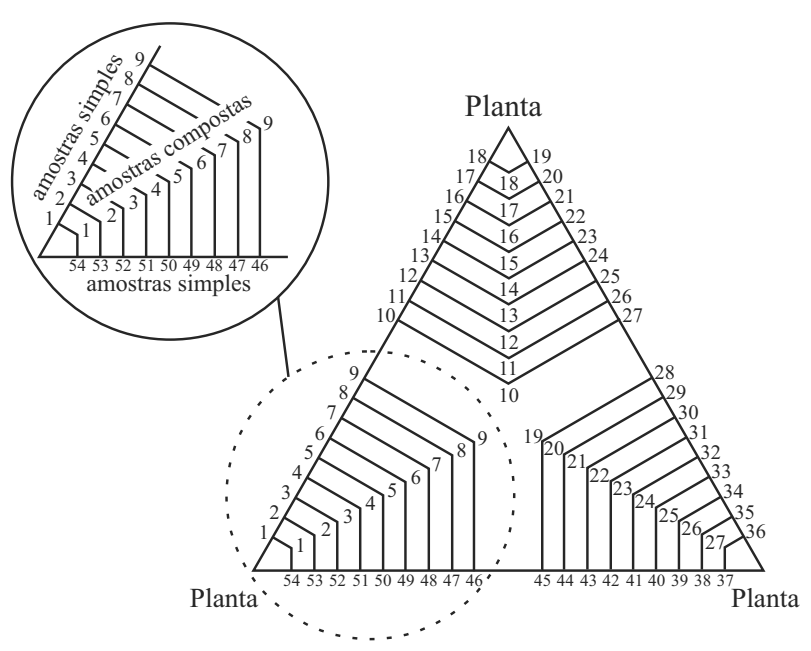

Figura 1 - Esquema de obtenção das amostras compostas

estudo, foram consideradas semelhantes. Assim, os 18 primeiros pontos amostrados a partir de cada planta (nove pontos em cada lado do triângulo) originaram nove amostras compostas de acordo com o esquema observado na Figura 1.

As frações areia, silte e argila foram obtidas por meio de dispersão química das partículas utilizando $\mathrm{NaOH}$ $1 \mathrm{~mol} \mathrm{~L}^{-1}$ e posterior agitação mecânica a $12.000 \mathrm{rpm}$ durante cinco minutos (EMBRAPA, 1997). A fração areia foi obtida por peneiramento por via úmida e separada em cinco classes de diâmetro: $2-1 ; 1-0,5 ; 0,5-0,25 ; 0,25-0,105$ e $0,105-0,053 \mathrm{~mm}$. No presente estudo considerou-se somente a classe de diâmetro 2-1 mm na avaliação da fração areia. A argila foi separada das demais frações pelo método da pipeta e os teores de silte foram calculados pela diferença entre os teores de areia e argila.

A extração das bases trocáveis no solo foi realizada com acetato de amônio $\mathrm{CH}_{3} \mathrm{COONH}_{4} 1 \mathrm{~N}$, na relação 1:10, conforme EMBRAPA (1997). Os teores de $\mathrm{Na}^{+}$ e $\mathrm{K}^{+}$trocáveis foram determinados por fotometria de chama, e os de $\mathrm{Ca}^{2+}$ e $\mathrm{Mg}^{2+}$ por espectrofotometria de absorção atômica. $\mathrm{O}$ fósforo $(\mathrm{P})$ disponível foi obtido pela extração com Mehlich-1 e quantificado por colorimetria. $\mathrm{O}$ pH foi obtido utilizando $\mathrm{KCl} 1 \mathrm{~mol} \mathrm{~L}^{-1}$ na relação 1:2,5 (EMBRAPA, 1997).

A condutividade elétrica do extrato de saturação do solo (CEes) foi medida por condutivímetro em extrato de solo na relação 1:3 após agitação mecânica e filtragem durante 60 minutos (RHOADES, 1981).

Adotou-se o delineamento experimental inteiramente casualizado com parcelas subdivididas. As distâncias horizontais entre os pontos de coleta e as camadas foram consideradas como parcelas e subparcelas, respectivamente. Cada área amostrada (AED e AER) foi analisada separadamente como um experimento independente não sendo comparadas entre si. Inicialmente, avaliou-se os parâmetros estatísticos relacionados com a média, tais como: desvio padrão (S) e coeficiente de variação $(\mathrm{CV})$. Cada média foi originada de três repetições. A ANOVA foi realizada com o auxílio do software SAEG 9.1 desenvolvido pela Universidade Federal de Viçosa, MG (SAEG, 2007).

Realizou-se o contraste de médias pelo teste T para um contraste usando a seguinte fórmula:

$\mathrm{T}=\mathrm{Xa}-\mathrm{Xb} /\left[\left(\mathrm{SQA}^{2}+\mathrm{SQB}^{2}\right) / 2 * 2 / \mathrm{n}\right]^{0,5}$

Tc 2(n - 1) graus de liberdade

onde, $\mathrm{Xa}$ e $\mathrm{Xb}$ são médias dos tratamentos a serem contrastadas, sendo considerado os pontos em diferentes distâncias em relação aos microaspersores para cada camada; e SQA ${ }^{2}$ e $\mathrm{SQB}^{2}$ são as variâncias das respectivas médias dos tratamento e $\mathrm{n}$ é número de repetições para compor a média.

Devido à ampla geração de comparações entre médias envolvendo as distâncias entre pontos de coleta e profundidades nas diferentes variáveis envolvidas no estudo, optou-se por representar o comportamento de cada variável por meio de mapas de superfície elaborados com auxílio do software SURFER (versão 7.0) utilizando interpolação por krigagem. Ressalta-se que os mapas de superfície não foram validados, sendo utilizados apenas como melhor forma de visualização dos resultados. As comparações entre médias foram devidamente testadas de acordo com os procedimentos estatísticos anteriormente descritos.

\section{Resultados e discussão}

Os teores de areia e silte (FIG. 2) não foram afetados significativamente pelo manejo da irrigação, corroborando com outros resultados na literatura. Por exemplo, Santos e Ribeiro (2000) avaliando a influência da irrigação e do cultivo nos atributos físicos de dois tipos de solos na região do submédio São Francisco, reportaram que as variações observadas na fração areia dos perfis estudados foram consequência da natureza do material de origem sem nenhuma relação com o manejo e cultivo dos solos. Em adição, Klepker e Anghinoni (1995) destacam que alterações entre as frações granulométricas em função do manejo são difíceis de ocorrer e, quando ocorrem, são detectadas a longo prazo. 
Os teores de argila sofreram incremento significativo em profundidade (FIG. 2) tanto na CI quanto na CNI independente do tipo de microaspersor utilizado, sugerindo que o tipo de microaspersor ou a irrigação não exerceram influência sobre esta variável. No entanto, na AED, na distância de 30 a $150 \mathrm{~cm}$ do emissor (CI), ocorreu aumento significativo de $1 \%$ nos teores de argila em subsuperfície em relação à CNI (FIG. 2), o que pode estar associado ao processo de dispersão devido à irrigação.
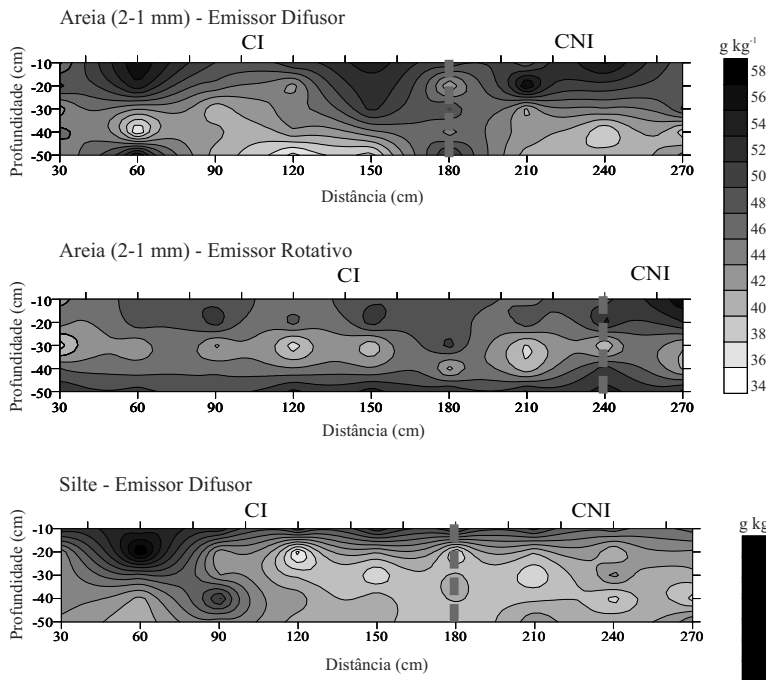

Silte - Emissor Rotativo
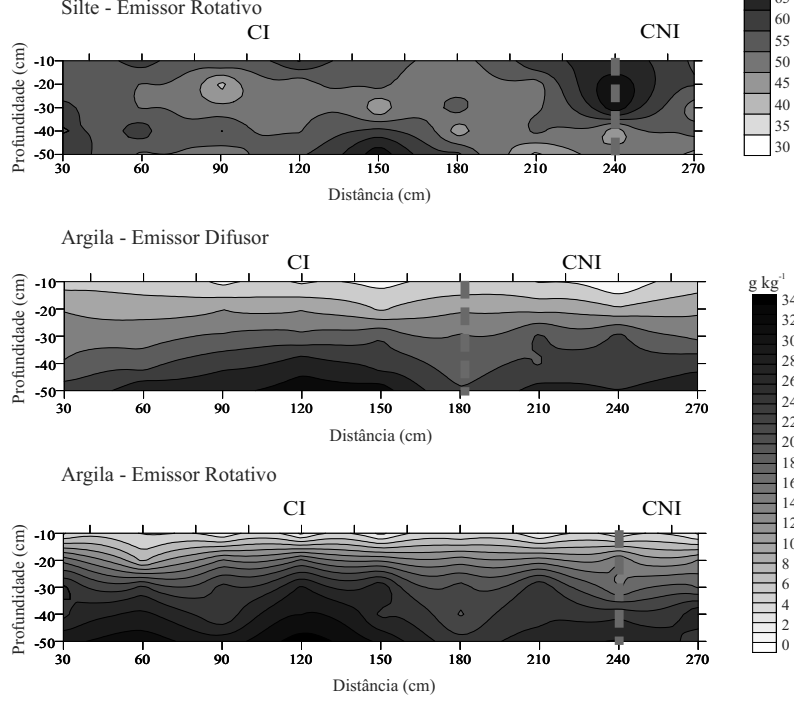

Figura 2 - Distribuição dos teores de areia, silte e argila de um Neossolo Quartzarênio cultivado com coqueiro anão em áreas fertirrigadas utilizando microaspersores do tipo difusor e rotativo no município de Paraipaba, Ceará. CI: condição irrigada; CNI: condição não irrigada. Barras na vertical indicam os limites entre a CI e CNI
O grau de dispersão das argilas aumenta quando há aumento dos níveis de salinidade (SPOSITO, 2008). Este efeito pode estar relacionado com má qualidade da água de irrigação utilizada no presente estudo, que apresentou valores de RAS de 3,75\% (TAB. 2), nível que implica em riscos para diminuição da infiltração de água segundo Ayers e Westcot (1994).

Em adição, Silva et al. (2005), estudando o efeito de sistemas de uso e manejo nas propriedades físicohídricas de um Argissolo amarelo de Tabuleiro Costeiro, discutem que áreas sob irrigação podem acentuar o grau de dispersão das argilas e, consequentemente, promover sua translocação e acúmulo nas camadas subsuperficiais do solo.

De modo geral, os teores de $\mathrm{Na}^{+}$foram maiores $(p<0,05)$ na CI em comparação a CNI e sofreram aumento significativo em profundidade independente do tipo de emissor utilizado (FIG. 3).

Este comportamento está associado à entrada do íon via água de irrigação, que apresentou valor de 4,15 mmol $\mathrm{L}^{-1}$ (TAB. 2), considerado acima do limite máximo de uso da água sem restrição para irrigação (AYERS; WESTCOT, 1994). Os teores de $\mathrm{Na}^{+}$ diminuíram com o aumento da distância do emissor até a zona de transição da região sob influência da irrigação. $\mathrm{Na}$ AED, nas camadas de 10-20 e de 20-30 cm, os teores de $\mathrm{Na}^{+}$foram, em média, cinco vezes maiores que os valores encontrados na CNI até a distância de $120 \mathrm{~cm}$ do emissor. Comportamento similar, porém em menores proporções, ocorreu na AER. A maior concentração de $\mathrm{Na}^{+}$nas áreas irrigadas, além da má qualidade da água $\left(\mathrm{Na}^{+}>3 \mathrm{mmol} \mathrm{L}{ }^{-1} ; \mathrm{RAS}=3,75 \%\right)$, pode está também associada com o nível de salinidade dos adubos químicos (PEIXOTO et al., 2006). O aumento de $\mathrm{Na}^{+}$ em profundidade expressa a facilidade de lixiviação do elemento pela água de irrigação (ANDRADE et al., 2004; BEN-HUR et al., 2001; LOPES et al., 2008) e pode significar um potencial risco de salinização caso o manejo da irrigação não esteja adequado às condições do solo.

Não houve efeito do tipo de emissor nos teores de $\mathrm{K}^{+}$ nas diferentes camadas de solo em ambas as condições de irrigação, com exceção das distâncias de $210 \mathrm{~cm}$ na AED (CNI) e de 210 e $240 \mathrm{~cm}$ na AER (CI), que apresentaram maiores teores de $\mathrm{K}^{+}$até $20 \mathrm{~cm}$ de profundidade em relação às demais camadas (FIG. 3). Possivelmente, a constante entrada desse elemento ao solo via água de irrigação, assim como a sua fácil mobilidade no solo (NEVES et al., 2009), esteja contribuindo para tal similaridade entre as camadas. Em ambas as áreas ocorreram menores teores de $\mathrm{K}^{+}$em pontos mais próximos aos emissores, o que pode estar relacionado com a absorção do elemento pela planta, 

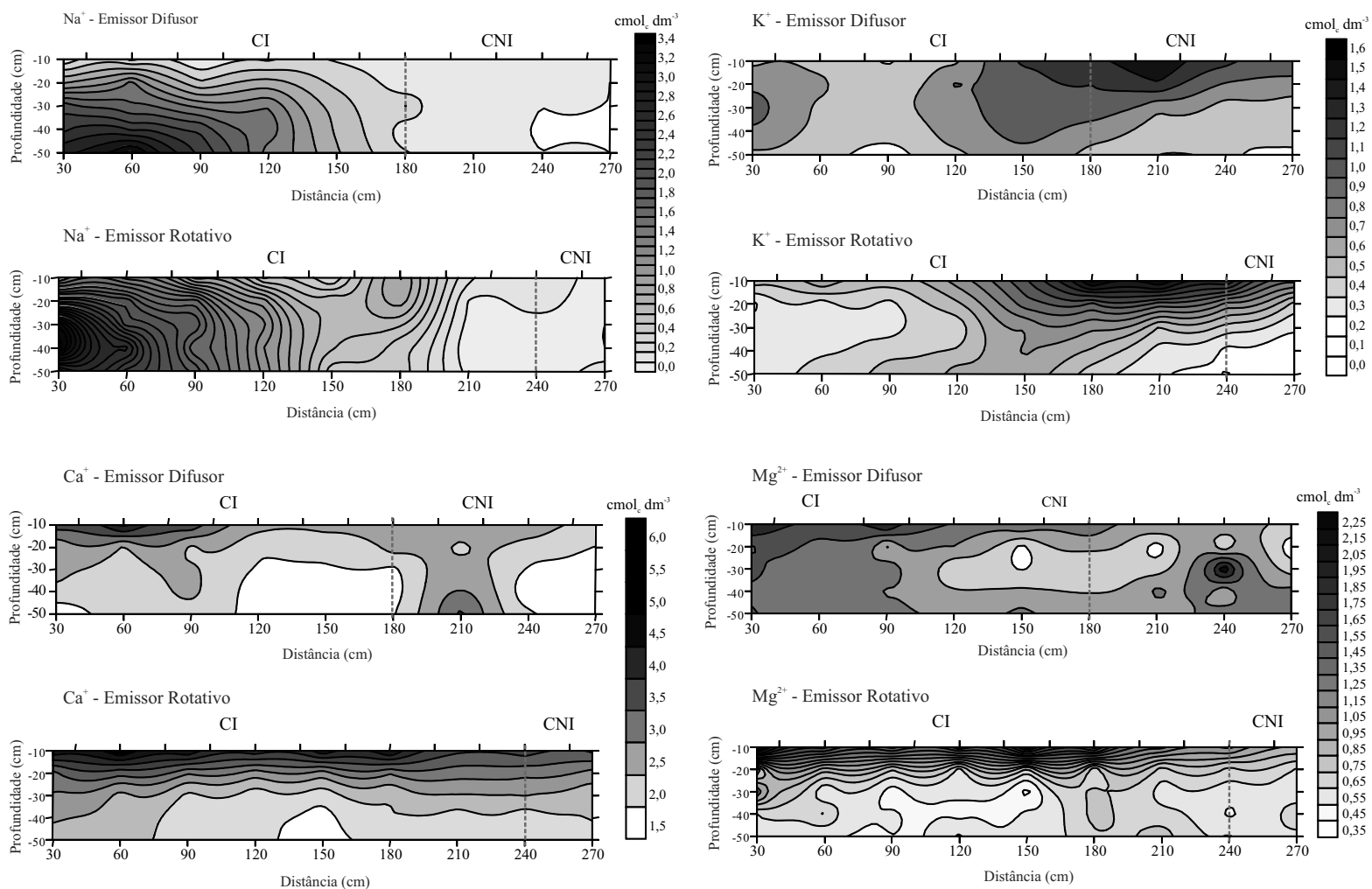

Figura 3 - Distribuição dos teores de $\mathrm{Na}^{+}, \mathrm{K}^{+}, \mathrm{Ca}^{2+}$ e $\mathrm{Mg}^{2+}$ trocáveis de um Neossolo Quartzarênio cultivado com coqueiro anão em áreas fertirrigadas utilizando microaspersores do tipo difusor e rotativo no município de Paraipaba, Ceará. CI: condição irrigada; CNI: condição não irrigada. Barras na vertical indicam os limites entre a CI e CNI

uma vez que $80 \%$ das raízes totais do coqueiro anão em plantas com 18 e 30 meses de idade estão entre 0,6 e 1,2 m de distância das plantas, respectivamente (MIRANDA et al., 2004). Tendências similares são encontradas em outras culturas, como na bananeira, onde reduções significativas nos teores de $\mathrm{K}^{+}$do solo ocorrem nas proximidades das plantas, especialmente em cultivos sob regime de irrigação (TEIXEIRA et al., 2001).

Os maiores teores de $\mathrm{Mg}^{2+}$ ocorreram na $\mathrm{CI}$ em relação à $\mathrm{CNI}$ em ambas as áreas avaliadas (FIG. 3). Na AED os teores foram superiores $(p<0,05)$ na CI até $90 \mathrm{~cm}$ de distância da planta e até $30 \mathrm{~cm}$ de profundidade. Já para a AER este efeito ocorreu até $210 \mathrm{~cm}$ de distância e a $20 \mathrm{~cm}$ de profundidade. Entretanto, existiram algumas exceções, como por exemplo, maiores teores de $\mathrm{Mg}^{2+}$ à $240 \mathrm{~cm}$ da planta (CNI) na camada de 20-30 cm na AED, o que pode estar atribuído à variabilidade espacial da área ou mesmo à resíduos de adubações anteriores. A maior concentração de $\mathrm{Mg}^{2+}$ na CI pode estar associada à entrada do elemento pela aplicação de calcário dolomítico a $90 \mathrm{~cm}$ da planta aos 24 meses, assim como pela água de irrigação (TAB. 2). A variabilidade dos teores de $\mathrm{Mg}^{2+}$ em superfície foi menor na AER, o que pode estar relacionado com o padrão de distribuição de água do emissor tipo rotativo que possui maior raio de alcance quando comparado ao outro tipo de emissor. Os teores de $\mathrm{Ca}^{2+}$ também foram maiores $(p<0,05)$ na $\mathrm{CI}$ em comparação à CNI independente do tipo de emissor até $20 \mathrm{~cm}$ de profundidade. Os maiores teores na CI ocorreram até 90 e $210 \mathrm{~cm}$ de distância do emissor nas áreas AED e AER, respectivamente. Assim como para o $\mathrm{Mg}^{2+}$, os teores de $\mathrm{Ca}^{2+}$ foram mais bem distribuídos em superfície na AER, sugerindo que este tipo de emissor favorece a estrutura radicular do coqueiro, que possui cerca de $50 \%$ da biomassa radicular nos primeiros $30 \mathrm{~cm}$ de profundidade (CINTRA et al., 1996), o que pode significar uma maior eficiência de absorção destes nutrientes. Esse resultado reforça a afirmação de que a distribuição de água no solo constitui uma variável determinante na distribuição de raízes no solo sob microirrigação (COELHO et al., 2002). Estudando a distribuição do sistema radicular da Mangueira sob irrigação localizada em solo arenoso de Tabuleiros Costeiros, Coelho et al. (2001) destacaram que o padrão 
de distribuição radicular no sistema de microaspersão reforçam a recomendação da fertirrigação como alternativa mais adequada de aplicação de fertilizantes ao solo, uma vez que todo o volume de solo explorado pelas raízes de absorção, especialmente as finas e muito finas, recebe os nutrientes num pequeno período de tempo, permitindo absorção quase simultânea por uma maior quantidade de raízes. Em outro estudo avaliando a distribuição do sistema radicular de laranja "Pêra" sob irrigação com microaspersão, Carvalho et al. (2002) reportaram que a distribuição de raízes pelo sistema de microaspersão mostrou maior uniformidade em torno da planta, o que viabiliza a aplicação de fertilizantes e a instalação de sensores de água no solo. Em adição, os autores destacam que a uniformidade de distribuição de água dos microaspersores em relação ao solo e às plantas resulta numa geometria de fluxo de água uniforme no solo, o que favorece o bom desenvolvimento e atividade das raízes.

Os teores de $\mathrm{P}$ disponível apresentaram comportamento comum nas áreas com emissores do tipo difusor e rotativo (FIG. 4). De modo geral, os maiores teores de $\mathrm{P}$ concentraram-se na camada de $0-20 \mathrm{~cm}$ até $120 \mathrm{~cm}$ de distância do emissor.

Este resultado reflete o efeito da adubação fosfatada realizada a 60; 90 e $120 \mathrm{~cm}$ na projeção da copa da planta, o que está de acordo com os resultados de Peixoto et al. (2006) que observaram variações nos teores de $\mathrm{P}$ em áreas irrigadas decorrentes da adubação fosfatada. A maior concentração de $\mathrm{P}$ em superfície e próximo aos pontos de aplicação do adubo deve-se à baixa mobilidade deste elemento no solo, que ocorre devido ao baixo valor do coeficiente de difusão do elemento no solo (NOVAIS; SMYTH, 1999; OLIVEIRA et al., 2004).

$\mathrm{O}$ pH do solo variou de 5,5 a 7,0 na AED e de 5,7 a 6,9 na AER (FIG. 4). Independente do tipo de emissor, observou-se que os maiores $(p<0,05)$ valores de $\mathrm{pH}$ ocorreram na CI na camada superficial, o que pode estar associado à constante recarga de sais solúveis oriundos da aplicação de fertilizantes ou mesmo pela entrada desses íons provenientes da água de irrigação.

Os maiores $(p<0,05)$ valores de condutividade elétrica do extrato de saturação do solo (CEes) ocorreram nas proximidades dos emissores em ambas as áreas avaliadas (FIG. 4). Tal comportamento foi mais evidente na AER em todas as camadas de solo até $90 \mathrm{~cm}$ de distância do emissor. De modo geral, os valores de condutividade elétrica foram significativamente maiores na CI em relação à CNI em praticamente todo o perfil do solo.
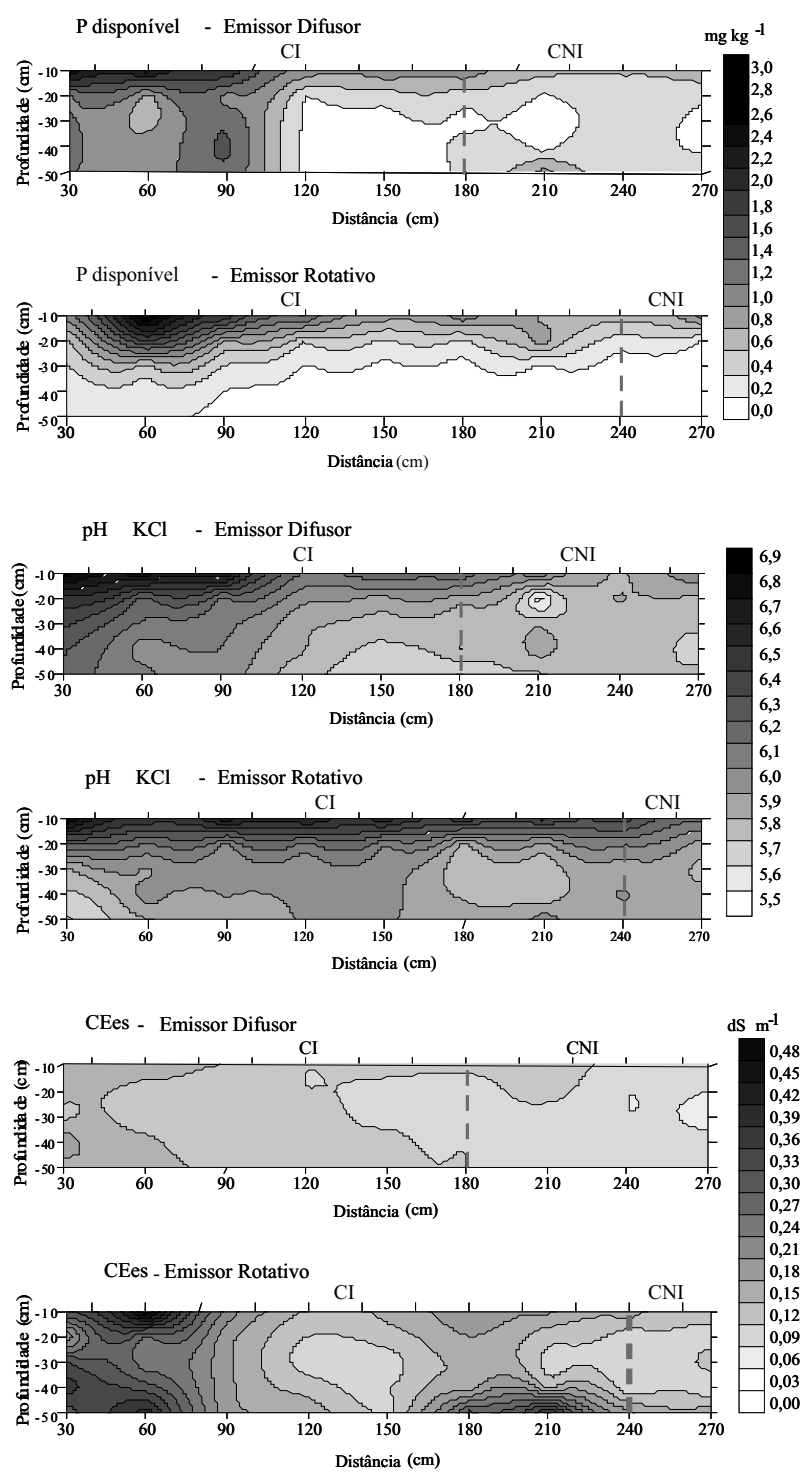

Figura 4 - Distribuição dos teores de $\mathrm{P}$ disponível, $\mathrm{pH}$ do solo e condutividade elétrica no extrato de saturação (CEes) de um Neossolo Quartzarênio cultivado com coqueiro anão em áreas fertirrigadas utilizando microaspersores do tipo difusor e rotativo no município de Paraipaba, Ceará. CI: condição irrigada; CNI: condição não irrigada. Barras na vertical indicam os limites entre a CI e CNI

$\mathrm{O}$ emissor tipo rotativo favorece maiores valores de CEes nas proximidades da planta, o que pode estar relacionado ao acúmulo de íons de $\mathrm{Na}^{+}$ (FIG. 3). Esse resultado sugere que, ao adotar esse tipo de emissor, o monitoramento dos níveis de salinidade nas proximidades da planta deva ser realizado com maior frequência, uma vez que o aumento unitário da salinidade acima de $0,2 \mathrm{dS} \mathrm{m}^{-1}$ representa riscos 
para a redução da produtividade de algumas culturas (GERVÁSIO et al., 2000). O sistema de classificação americana para solos afetados por sais (RICHARDS, 1954) aponta que valores de CEes acima de $4 \mathrm{dS} \mathrm{m}^{-1}$ resultam na redução em $50 \%$ da produção da maioria das culturas. Marinho et al. (2006) reportaram que o aumento unitário da condutividade elétrica da água de irrigação reduz o número e o peso de frutos do coqueiro 'Anão Verde' em 2 e 3,4\%, respectivamente, e que a condutividade elétrica da água de irrigação de $10 \mathrm{dS} \mathrm{m}^{-1}$ foi o limite para se obter produção aceitável de frutos de coqueiro 'Anão verde'. Resultados semelhantes foram obtidos por Ferreira Neto et al. (2002).

\section{Conclusões}

1. A irrigação localizada com microaspersores do tipo difusor e rotativo, no período de 30 meses, não promoveu alterações na granulometria do solo. Entretanto, os resultados sugerem que a influência do manejo da irrigação sobre os atributos físicos devam ser monitoradas a longo prazo;

2. Os atributos químicos do solo foram sensivelmente afetados pela fertirrigação. A irrigação favorece acúmulo de $\mathrm{Ca}^{2+}, \mathrm{Mg}^{2+}$ e $\mathrm{P}$ disponíveis nas proximidades dos microaspessores em superfície, e de $\mathrm{Na}^{+}$em profundidade, de acordo com a característica de mobilidade de cada elemento. $\mathrm{O}$ acréscimo de $\mathrm{Na}^{+}$ em profundidade implica em um potencial risco de salinização, sugerindo que o manejo da irrigação deve considerar não somente o tipo de microaspersor, mas especialmente a qualidade da água de irrigação e o comportamento das características físicas e químicas do solo.

\section{Agradecimentos}

Os autores agradecem à Embrapa Agroindústria Tropical/CNPAT pela concessão da área experimental e apoio técnico; ao CNPq pelas bolsas ligadas aos programas de iniciação científica/PIBIC e produtividade à pesquisa; à Fundação Cearense de Apoio ao Desenvolvimento Científico e Tecnológico (FUNCAP) pelo auxílio financeiro.

\section{Referências}

ANDRADE, E. M. et al. Evolução da concentração iônica da solução do solo em áreas irrigadas na Chapada do Apodi. Revista Ciência Agronômica, v. 35, n. 01, p. 09-16, 2004.
AYERS, R. S.; WESTCOT, D. W. Water quality for agriculture. Rome: Food and Agriculture Organization of the United Nations1994 (Reprinted). (Fao Irrigation and Drainage Paper, 29 Rev. 1). Disponível em: <http://www. fao.org/DOCREP/003/T0234E/T0234E00.HTM> Acesso em: 10 abr. 2011.

BEN-HUR, M. et al. Water and salt distribution in a field irrigated with marginal water under high water table conditions. Soil Science Society of American Journal, v. 65, p. 191-198, 2001.

BRASIL. Ministério da Agricultura. Divisão de Pesquisa Pedológica. Levantamento Exploratório. Reconhecimento de Solos do Estado do Ceará. Recife,. 1973. 310 p. (Série Pedologica,16).

CARLESSO, C. J. M. R. et al. Qualidade física de solos irrigados do Estado do Rio Grande do Sul. Ciência Rural, v. 37, n. 05, p. 1308-1315, 2007.

CINTRA, F. L. D.; FONTES, H. R.; LEAL, M. L. S. Distribuição do sistema radicular do coqueiro gigante do Brasil submetido a diferentes sistemas de manejo do solo. Revista Brasileira de Ciência do Solo, v. 20, p. 327-332, 1996.

COELHO, E. F. et al. Distribuição do sistema radicular da mangueira sob irrigação localizada em solo arenoso de tabuleiros costeiros. Revista Brasileira de Fruticultura, v. 23 , n. 02 , p. $250-256,2001$.

COELHO, E. F. et al. Distribuição de raízes de laranja "Pêra" sob sequeiro e irrigação por microaspersão em solo arenoso. Pesquisa Agropecuária Brasileira, v. 37, n. 05, p. 603-611, 2002.

CORRÊA, R. M. et al. Atributos químicos de solos sob diferentes usos em perímetro irrigado no semiárido de Pernambuco. Revista Brasileira de Ciência do Solo, v. 33, n. 02, p. 305-314, 2009.

EMPRESA BRASILEIRA DE PESQUISA AGROPECUÁRIA (EMBRAPA). Manual de métodos e análises de solo. Rio de Janeiro: EMBRAPA, 1997. 152 p.

FERREIRA NETO, M. et al. Qualidade do fruto verde de coqueiro em função da irrigação com água salina. Revista Brasileira de Engenharia Agrícola e Ambiental, v. 06, n. 01, p. $69-75,2002$.

FREITAS, E. V. S. et al. Alterações nos atributos físicos e químicos de dois solos submetidos à irrigação com água salina. Revista de Biologia e Ciências da Terra, v. 07, n. 01, p. 21-28, 2007.

GERVÁSIO, E. S.; CARVAlHO, J. A.; SANTANA, M. J. Efeito da salinidade da água de irrigação na produção da alface americana. Revista Brasileira de Engenharia Agrícola e Ambiental, v. 04, n. 01, p. 125-128, 2000.

HERNANI, L. C.; KURIHARA, C. H.; SILVA, W. M. Sistemas de manejo de solo e perdas de nutrientes e matéria orgânica por erosão. Revista Brasileira de Ciência do Solo, v. 23, p. 145-154, 1999.

INSTITUTO DE PESQUISA E ESTRATÉGIA ECONÔMICA DO CEARÁ (IPECE). Perfil Básico Municipal. Ceará, 2005. $10 \mathrm{p}$. 
KLEPKER, D.; ANGHINONI, I. Características físicas e químicas do solo afetadas por métodos de preparo e modos de adubação. Revista Brasileira de Ciência do Solo, v. 19, p. 395-401, 1995.

LOPES, J. F. B.; ANDRADE, E. M.; CHAVES, L. C. G. Impacto da irrigação sobre os solos de perímetros irrigados na Bacia do Acaraú. Engenharia Agrícola, v. 28, n. 01, p. 34-43, 2008.

LYRA, M. C. P.; RIBEIRO, M. R.; RODRIGUES, J. J. V. Caracterização de Vertissolos em projetos de irrigação na região do baixo-médio São Francisco: II - Propriedades Morfológicas, Físicas e Químicas. Revista Brasileira de Ciência do Solo, v. 19, p. 441-448, 1995.

MARINHO, F. J. L. et al. Cultivo de coco 'Anão Verde' irrigado com águas salinas. Pesquisa Agropecuária Brasileira, v. 41, n. 08 , p. 1277-1284, 2006.

MEDEIROS, R. D.; ARAÚJO, W. F.; COSTA, M. C. Efeito de sistemas de preparo do solo e métodos de irrigação sobre a cultura do caupi em várzeas em Roraima. Revista Brasileira de Engenharia Agrícola e Ambiental, v. 09, n. 02, p. 205-209, 2005.

MIRANDA, J. R. et al. Distribuição do sistema radicular de plantas jovens de coqueiro-anão sob diferentes freqüências de irrigação. Revista Ciência Agronômica, v. 35, p. 139147, 2004.

NEVES, L. S.; ERNANI, P. R.; SIMONETE. M. A. Mobilidade de potássio em solos decorrente da adição de doses de cloreto de potássio. Revista Brasileira de Ciência do Solo, v. 33, n. 01, p. 25-32, 2009.

NOVAIS, R. F.; SMYTH, T. J. Fósforo em solo e planta em condições tropicais. Viçosa: UFV-DPS. 1999. 399 p.

NUNES, W. A. G. A. et al. Características químicas de solos da região de Janaúba, MG, irrigados com água de poços tubulares e do rio Gorutuba. Revista Brasileira de Ciência do Solo, v. 32, p. 227-236, 2008.

OLIVEIRA, E. M. M. et al. Fatores de retardamento e coeficientes de dispersão-difusão de fosfato, potássio e amônio em solos de Minas Gerais. Revista Brasileira de Engenharia Agrícola e Ambiental, v. 08, n. 02/03, p. 196-203, 2004.
PEIXOTO, J. F. S.; GUERRA, H. O. C.; CHAVES, L. H. G. Alterações de atributos químicos do solo pela fertirrigação com nitrogênio e potássio. Agropecuária Técnica, v. 27, n. 02, p. 69-76, 2006.

RHOADES, J. D.; CORWIN, D. L. Determining soil electrical conductivity-depth relations using an inductive electromagnetic soil conductivity meter. Soil Science Society of America Journal, v. 45, n.02, p. 255-260, 1981.

RICHARDS, L. A. Diagnosis and improvement of saline and alkali soils. Washington, US Department of Agriculture, 1954. 160 p. (USDA Agricultural Handbook, 60).

SANTOS, E. E. F.; RIBEIRO, M. R. Influência da irrigação e do cultivo nas propriedades de um Latossolo e um Argissolo da região do submédio São Franciso: Atributos morfológicos e físicos. Revista Brasileira de Ciência do Solo, v. 24, p. 875-884, 2000.

SILVA, A. J. N.; CABECA, M. S. V.; LIMA, J. F. W. F. Efeitos de sistemas de uso e manejo nas propriedades físico-hídricas de um Argissolo Amarelo de tabuleiro costeiro. Revista Brasileira de Ciência do Solo, v. 29. p. 833-842, 2005.

SISTEMA para Análises Estatísticas (SAEG), Versão 9.1. Viçosa: Fundação Arthur Bernardes, 2007.

SOBRAL, L. F.; NOGUEIRA, L. C. Influência de nitrogênio e potássio, via fertirrigação, em atributos do solo, níveis críticos foliares e produção do coqueiro-anão. Revista Brasileira de Ciência do Solo, v. 32. p. 1675-1682, 2008.

SOBRAL, L. F. Nutrição e adubação do coqueiro. In: FERREIRA, J. M. S.; WARWICK, D. R. N.; SIQUEIRA, L. A. A cultura do coqueiro no Brasil. Brasília: EMBRAPA, 1997. p. 129-157.

SPOSITO, G. The chemistry of soils. New York: Oxford University Press. 2008. 329 p.

TEIXEIRA, L. A. J.; NATALE, W.; RUGGIERO, C. Alterações em alguns atributos químicos do solo decorrentes da irrigação e adubação nitrogenada e potássica em bananeira após dosi ciclos de cultivo. Revista Brasileira Fruticultura, v. 23, p. 684-689, 2001. 